\title{
Comparative effectiveness of means to reduce negative effects of lead, cadmium and nitrates
}

\author{
Vasily Dorozhkin, Galina Pavlenko, Natalia Pavlova*, and Dmitry Drozdov
}

All-Russian Research Institute for Veterinary Sanitation, Hygiene and Ecology - Branch of Federal State Budget Scientific Institution Federal Scientific Center - K.I. Skryabin, Ya.R. Kovalenko All-Russian Research Institute of Experimental Veterinary Medicine, Russian Academy of Sciences, Moscow, 123022, Russia

\begin{abstract}
According to the constant deterioration of the environmental situation, the issue of preserving health of agricultural animals and obtaining safe livestock products is acute. One of the most effective ways to reduce the accumulation and ecotoxicants impact is pharmacological drugs usage and feed additives with different mechanisms of action. A comparative assessment of various agents exposed to heavy metals and nitrates in laboratory animals is presented. It was found that using feed with an increased content of heavy metals and nitrates increased the level of ecotoxicants in the organs and tissues of animals. Solvimin selenium enabled to reduce the accumulation of cadmium and lead in organism (up to $45 \%$ ), restore the normal amount of hemoglobin and the summation threshold, animals' weight, protein and carbohydrate metabolism. However, it did not restore the indicators of the liver and kidneys functional state. The use of laricarvit showed a fairly high protective efficiency in removing cadmium (25$30 \%$ ) and reducing the nitrates accumulation in the blood and muscles, normalizing the body weight of animals, the number of white blood cells, lymphocytes and methemoglobin. Detox injections successfully reduced the content of nitric nitrogen in the blood, in the liver and, to some extent, in the kidneys, while complete normalization of blood parameters was not observed.
\end{abstract}

\section{Introduction}

One of the most important environmental tasks is to prevent environmental pollution and provide rehabilitation of ecosystems polluted with ecotoxicants.

In nature, ecotoxicants are rarely found in isolation from each other. A variety of combinations and their concentrations in the medium lead to changes in the properties of individual elements as a result of a synergistic or antagonistic effect on living organisms.

It has been shown that the total toxicological effect of environmental pollution by heavy metals (HM) depends not only on the set and level of specific elements but also on the characteristics of their mutual effects on the body [1-3].

Due to the intensive use of chemicals in the technology of growing crops and animals, the need for strict quality control of food and animal feed has arisen $[4,5]$. It is subject to heavy metals, nitrates, pesticide residues and other substances that can and often do have a negative effect on human and animal health.

Artificial fertilizers being the main source of nitrate accumulation in the environment can consist of a number of different compounds, including ammonium, calcium, potassium, sodium, and urea nitrates. The production of nitrogen fertilizers is constantly growing in the world [6].

The dynamics of ecotoxicants accumulation, absorption and excretion, distribution of organs and tissues is important for understanding the picture of poisoning, assessing the degree of their toxic effect and using this data for the poisoning treatment $[5,7]$.

Studies on the use of antidotes, sorbents and adaptogens are relevant along with the issues of preventing the penetration of pollutants into adjacent environments and their rehabilitation [4, 8]. This is consistent with the hypothesis of microelementary mineral imbalance that occurs in the body under the action of metals [1, 4].

Among the means to reduce the negative effect of ecotoxicants, an important role is played by sorptiondetoxification substances, different in origin and mechanism of detoxifying (antidotes, sorbents, ionexchange substances, chelates).

With the development of anthropogenic and environmental organopathologies and diseases that accompany and enhance the negative impact of ecotoxicants, it is necessary to use a wider range of pharmacological agents, in particular immunomodulators, antioxidants, vitamin-mineral supplements and other biologically active substances (BAS), which contribute to farm animals' health and productivity restoration [8].

The aim of this research is to study the biological effects of pharmacological agents that are promising as protectors for poisoning with heavy metals and nitrates in the laboratory. 


\section{Materials and methods}

Experimental studies were conducted in the All-Russian Research Institute of Veterinary Sanitation, Hygiene and Ecology vivarium on 2 animal species being white male rats and rabbits.

During the experiments, they were guided by the moral and ethical standards of humane treatment of laboratory animals. Generally accepted toxicological methods were used to assess the health status of animals $[9,10]$. The heavy metal content was determined by atomic absorption on a Varian AA 240 FS instrument. Samples were subjected to hot acid mineralization.

In the first series of experiments, one group of animals (white rats) received salts of lead and cadmium in doses of pure lead (50 mg/kg of feed) and of pure cadmium (5.0 $\mathrm{mg} / \mathrm{kg}$ of feed) together with their food. The second group together with metals in the same doses received solvimin selenium in a dose of $0.5 \mathrm{~g} / \mathrm{l}$ with drink. In the third group being a control one, the animals received normal food and water. The experiment lasted for 1.5 months. During the experiment, animals were examined using clinical, immunological and biochemical tests $[9,10]$.

In the next series of experiments, the effect of protectors on complex poisoning with heavy metals and nitrates was studied. Rabbits received nitrates with haylage after introduction of bedded manure into the soil. The cadmium content in the silage was $1.85 \mathrm{mg} / \mathrm{kg}$, and the total amount of nitrates $\left(\mathrm{N}-\mathrm{NO}_{3}\right)$ was $167.0 \mathrm{mg} / \mathrm{kg}$ of body weight.

Against the background of increased intake of heavy metals and nitrates, the protective agents (gamavit, detox and laricarvit) were used in therapeutic doses.

Gamavit is a drug used to increase natural resistance, immunocorrection and reduce the effects of intoxication in animals and birds. It contains such active substances, sodium nucleinate, acid-hydrolyzed placenta-denaturedemulsified (PDE) and medium 199.

Detox is a drug prescribed to animals for treating diseases associated with intoxications of various origins. Detox contains sodium thiosulfate and low molecular weight polyvinylpyrrolidone as active ingredients. Detox was injected under the skin every second day in an amount of $2 \mathrm{ml}$.

Laricarvit is a biologically active substance containing spruce chlorophyll, beta-carotene, a bioflavonoid complex of larch, vitamins A, D, E. Its use corrects Avitamin nutrition and increases some factors of nonspecific defense of the body.

The analysis of peripheral blood was carried out on a hematological analyzer "Medonic" CA 620 Balder. The functional state of the central nervous system was evaluated by the summation-threshold index. The neuromuscular excitability of animals was determined using electrodes to reduce interdigital muscles with an increase in current supply [11].

At the end of the experiment, the number of SH groups was determined in blood serum. The method is based on the equivalent interaction of molecular iodine with free $\mathrm{SH}$-groups of proteins and low molecular weight compounds in the presence of $1 \mathrm{M} \mathrm{KJ}$ and phosphate buffer $(\mathrm{pH}=7.6)$.

The amount of iodine that reacted with SH groups was judged by comparing the experimental and control samples by means of filter photometer [12].

The study of kidneys functional state was carried out according to a set of methods. Diuresis was measured, urine specific gravity, protein and chloride content in the urine were determined. After the experiment, the animals were killed and the mass coefficients of the internal organs were determined.

When studying liver functional state, we used indicators characterizing the neutralizing and proteinforming functions. Liver neutralizing function was evaluated by the ability of an organ to synthesize hippuric acid [13]. The protein-forming function of animals' liver was judged by the content of total protein in the blood serum (refractometric method).

Statistical processing of the results was carried out according to the Student method in the Tippet modification [14] in Excel 2010.

\section{Results and Discussion}

Contamination of feed with salts of heavy metals led to a significant (7-8 times) increase in the level of cadmium and lead in animals' bodies. The maximum level of HM was stated in kidneys and liver. In muscle tissue, the amount of lead and cadmium was almost 2-3 times higher than the maximum allowable concentration of this element for meat products (Table 1).

Table 1. Effect of solvimine selenium on lead and cadmium content in rat organs and tissues after 1.5 months of the experiment, $\mathrm{mg} / \mathrm{kg}$

\begin{tabular}{|c|c|c|c|c|}
\hline $\begin{array}{c}\text { Tissues } \\
\text { and } \\
\text { organs }\end{array}$ & $\mathrm{HM}$ & $\mathrm{HM}$ & $\begin{array}{c}\mathrm{HM}+ \\
\text { solvimin } \\
\text { selenium }\end{array}$ & Control \\
\hline \multirow{2}{*}{ Liver } & $\mathrm{Cd}$ & $1.27 \pm 0.75$ & $0.72 \pm 0.05$ & $0.15 \pm 0.01$ \\
\cline { 2 - 5 } & $\mathrm{Pb}$ & $3.27 \pm 0.21$ & $1.93 \pm 0.09$ & $0.35 \pm 0.02$ \\
\hline Kidney & $\mathrm{Cd}$ & $1.85 \pm 0.15$ & $0.98 \pm 0.09$ & $0.23 \pm 0.02$ \\
\cline { 2 - 5 } & $\mathrm{Pb}$ & $5.82 \pm 0.39$ & $3.72 \pm 0.20$ & $0.52 \pm 0.04$ \\
\hline Muscles & $\mathrm{Cd}$ & $0.13 \pm 0.01$ & $0.07 \pm 0.03$ & $0.02 \pm 0.01$ \\
\cline { 2 - 5 } & $\mathrm{Pb}$ & $1.68 \pm 0.09$ & $0.96 \pm 0.43$ & $0.17 \pm 0.01$ \\
\hline
\end{tabular}

where $\mathrm{P}<0.05$.

As follows from the table, the use of the drug solvimin selenium showed high efficiency and led to a decrease in the HM cumulation in rat organs (up to $45 \%$ ). However, the cadmium content in muscle tissue at the level of 0.07 $\mathrm{mg} / \mathrm{kg}$ still exceeded the MAC for meat products by one and half times.

Solvimin selinium has shown a rather high efficiency in reducing animal intoxication. It restored to normal hemoglobin and summation-threshold index, increased the body weight of animals, and normalized protein and carbohydrate metabolism indicators.

However, it turned out to be less effective in relation to indicators characterizing the functional state of liver and kidneys. An increase in the content of alkaline phosphatase, urea as well as liver weights remained significantly high. 
Thus, the use of the drug solvimin selenium alone did not allow reaching the necessary level of animal organism detoxification in case of poisoning with cadmium and lead salts. However, the drug can be offered for being used as a part of complex therapy for animals' intoxication.

Protective effect of gamavit was evaluated in a series of experiments where laboratory animals received "nitrate" haylage with a high content of heavy metals. At the same time, there was a significant accumulation of nitrates in blood, liver and muscles.

And this is logical, since it is known that when nitrates enter the body with feed, their absorption into blood begins already in the small intestine, and the liver belongs to the organs that are the first targets for the toxic effect of nitrates when they are ingested in oversize amount $[6,15]$.

After the experiment, the cadmium content was determined in organs of animals receiving haylage with $\mathrm{HM}$ and in groups where gamavit was administered to animals against the background of poisoning (Table 2).

Table 2. Cadmium content in rabbits' organs (gamavit), $\mathrm{mg} / \mathrm{kg}$

\begin{tabular}{|l|l|l|l|}
\hline $\begin{array}{l}\text { Tissues } \\
\text { and organs }\end{array}$ & $\mathrm{HM}$ & $\mathrm{HM}$ & $\begin{array}{l}\mathrm{HM}+ \\
\text { solvimin } \\
\text { selenium }\end{array}$ \\
\hline Kidney & $0.42 \pm 0.04$ & $0.31 \pm 0.03$ & $0.22 \pm 0.02$ \\
\hline Liver & $0.59 \pm 0.05$ & $0.41 \pm 0.03$ & $0.31 \pm 0.02$ \\
\hline Muscles & $0.02 \pm 0.01$ & $0.02 \pm 0.01$ & $0.02 \pm 0.01$ \\
\hline
\end{tabular}

where $\mathrm{P}<0.05$.

A significant, statistically valid increase in cadmium content in the liver and kidneys of the rabbits of the experimental group was noted. So in the kidneys, the level of this element increased from 0.22 to $0.42 \mathrm{mg} / \mathrm{kg}$, and in the liver from 0.31 to $0.59 \mathrm{mg} / \mathrm{kg}$. The use of gamavit led to a decrease in the concentration of nitrate in the blood, kidneys and muscles by $30-40 \%$ and cadmium by $25-30$ $\%$. Gamavit against the background of nitrate and HM poisoning caused a significant increase (at $\mathrm{P}<0.05$ ) in rabbit body weight, normalization of leukocyte, lymphocyte, platelet and immunoglobulin counts.

Thus, gamavit has shown a rather high efficiency in the removal of cadmium and nitrates from the body of animals in case of their increased content in the diet.

The protective effect of laricarvit was evaluated by changing the content of nitrate nitrogen and cadmium in organs and tissues and the functional state of the body. When determining the accumulation of $\mathrm{N}^{-\mathrm{NO}_{3}}$ in the organs and tissues of the animals, a significant accumulation of nitrates in the blood, liver and muscles was noted.

When determining cadmium, a significant, statistically valid increase in its content in the liver and kidneys of the rabbits of the experimental group was also observed. So in the kidneys, the level of this element increased from 0.22 to $0.42 \mathrm{mg} / \mathrm{kg}$, and in the liver from 0.31 to 0.59 $\mathrm{mg} / \mathrm{kg}$ (Table 3).

Detox in the amount of $2 \mathrm{ml}$ in the form of 6 -fold injections was used against the background of nitrate poisoning. At the same time, under the influence of the liquid fraction of bedless manure, the content of nitrate nitrogen in the soil and grass was almost 1.5 times higher than its content in control environments.
A significant increase in nitrate nitrogen was observed in the blood and kidneys of the rabbits receiving haylage from a field treated with liquid manure. An increase in nitrate was not significant in the liver but the tendency of it increase was observed (Table 4).

Table 3. Nitrate nitrogen content in animals' organs and tissues after 1.5 months of the experiment (larikarvit), $\mathrm{mg} / \mathrm{kg}$

\begin{tabular}{|l|l|l|l|l|}
\hline \multirow{2}{*}{ Groups } & \multicolumn{4}{|l|}{ Nitrate nitrogen $\left(\mathrm{N}-\mathrm{NO}_{3}\right)$} \\
\cline { 2 - 5 } & llood & Kidney & Liver & Muscles \\
\hline Nitrates & $56.7 \pm 7.5^{*}$ & $29.6 \pm 1.8$ & $20.8 \pm 1.3^{*}$ & $33.3 \pm 1.5^{*}$ \\
\hline $\begin{array}{l}\text { Nitrates + } \\
\text { larikarvit }\end{array}$ & $28.7 \pm 9.8^{* *}$ & $28.7 \pm 1.5$ & $17.1 \pm 1.5$ & $25.4 \pm 2.5^{* *}$ \\
\hline Control & $25.8 \pm+8.5^{* *}$ & $23.2 \pm 1.6$ & $14.7 \pm 1.1$ & $25.8 \pm 2.3^{* *}$ \\
\hline
\end{tabular}

$*$ is $\mathrm{P}<0.05$ compared to control group;

** is $\mathrm{P}<0.05$ compared to nitrate group.

Table 4. Nitrate content in rabbits' organs and tissues (detox)

\begin{tabular}{|c|c|c|c|c|}
\hline Study object & Groups & \multicolumn{2}{|c|}{$\mathrm{NO}_{3}$} & \multirow{2}{*}{$\begin{array}{c}\text { N-NO } \\
(\mathrm{mg} / \mathrm{kg})\end{array}$} \\
\cline { 3 - 4 } & & $\mathrm{mg} / \mathrm{l}$ & $\mathrm{mg} / \mathrm{kg}$ & \\
\hline \multirow{3}{*}{ Blood } & Nitrates & 126 & 900 & $203.3 \pm 20.0^{*}$ \\
& $\begin{array}{c}\text { Nitrates }+ \\
\text { Detox }\end{array}$ & 122 & 580 & $131.2 \pm 16.2$ \\
& Control & 120 & 632 & $142.0 \pm 13.1$ \\
\hline \multirow{4}{*}{ Liver } & Nitrates & 108 & 519 & $117.2 \pm 11.3$ \\
& Nitrates + & & & \\
& Detox & 109 & 406.7 & $91.9 \pm 13.7$ \\
& Control & 97.5 & 399.6 & $90.3 \pm 9.1$ \\
\hline \multirow{4}{*}{ Kidney } & Nitrates & 127 & 635.0 & $143.0 \pm 8.5^{*}$ \\
& Nitrates + & & & \\
& Detox & 125 & 618.8 & $139.8 \pm 10.2^{*}$ \\
& Control & 127 & 635.0 & $101.4 \pm 9.8$ \\
\hline \multirow{2}{*}{ Muscles } & Nitrates & 90.8 & 412.7 & $93.2 \pm 7.1$ \\
& Nitrates + & & & \\
& Detox & 87.7 & 413.7 & $93.4 \pm 8.7$ \\
& Control & 88.9 & 449.0 & $92.0 \pm 7.3$ \\
\hline
\end{tabular}

where $\mathrm{P}<0.05$

The nitrate content in the muscles of the animals of the experimental groups was on the same level as the control group. Intramuscular injections of detox have successfully reduced the content of nitrate nitrogen in the blood, liver and, to some extent, in the kidneys.

When analyzing the functional parameters of the organism of rabbits receiving grass from areas fertilized with liquid manure, a significant increase in methemoglobin and a decrease in platelets were noted (Table 5).

Table 5. Determination of platelets and methemoglobin in rabbits' blood

\begin{tabular}{|c|c|c|c|}
\hline Groups & Nitrates & $\begin{array}{c}\text { Nitrates }+ \\
\text { Detox }\end{array}$ & Control \\
\hline Platelet & $177.3 \pm 12.8 \mathrm{P}<$ & $163.3 \pm 26.8$ & $336.5 \pm 40.0$ \\
& 0.05 & $\mathrm{P}<0.05$ & \\
\hline Methemoglobin & $14.1 \pm 2.9$ & $6.3 \pm 2.0$ & $2.1 \pm 0.1$ \\
& $\mathrm{P}<0.05$ & $\mathrm{P}<0.05$ & \\
\hline
\end{tabular}

It is known that the main effect of nitrates and nitrites is methemoglobinemia induction [6]. Detox slightly reduced the level of methemoglobin but the content of this pigment remained significantly high. 
Platelets continued to remain at the same level. Sixfold use of this drug was not enough for complete detoxification of the animal organism.

\section{Conclusion}

Thus, it was found that the introduction feed with an overestimated level of heavy metals and nitrates into the animals' diet led to an increase in the number of the above ecotoxicants in the organs and tissues of animals. The use of solvimin selenium caused a decrease in the content of heavy metals in the animal organism and normalization of most functional indicators. However, we consider it advisable to use this drug in combination with other drugs for higher efficiency of therapy for intoxication.

The use of gamavit, detox and larikarvit led to a significant redistribution of nitrate nitrogen in the body of rabbits. Thus, when using gamavit, the content of nitrate nitrogen in the blood decreased by half, in the kidneys by $20 \%$, in the liver by a third, in the muscles it was close to the control values.

The drug gamavit has shown a rather high efficiency in removing heavy metals from animals (25-30\%) with a high content of an element in the diet and can be offered for being used as a part of complex therapy for intoxication of animals with heavy metal compounds.

Similar results were obtained using larikarvit, which effectively participated in the excretion of cadmium from the animal organism, reduced the accumulation of nitrates in the blood and muscles, and also helped to restore indicators that changed under the influence of these ecotoxicants.

In addition, larikarvit can be used with food, which is much more technologically advanced when growing farm animals.

The use of detox has led to a decrease in the content of nitrate nitrogen in the blood, in the liver and, to some extent, in the kidneys, which suggests that under the conditions of longer use, the drug may be more effective for detoxifying the animal's body in case of nitrate poisoning.

This tool as well as solvimin selenium can be recommended for use as part of a complex therapy for animals' intoxication.

Based on the data obtained it was concluded that the most effective is the use of a complex of detoxifying agents having different mechanisms of action and complementing each other $[2,8]$.

\section{References}

1. T.I. Bokova, Patterns of detoxification of anthropogenic pollutants (heavy metals) in the soil plant - animal system - human food, doctoral dissertation (Novosibirsk, 2005)
2. G.I. Pavlenko, N.S. Pavlova, D.A. Drozdov, N.A. Brichko, V.I. Dorozhkin, Screening and study of the biological effect of drugs to reduce the negative impact of ecotoxicants on the animal organism, Russ. J. of Probl. of Veterin. Sanit., Hygiene and Ecol., 2(30), 216-223 (2019)

3. Yu.A. Gavrilov, Pharmacological correction of metabolic disorders in farm animals caused by the action of ecotoxicants, doctoral dissertation thesis (Voronezh, 2007)

4. A.M. Malov, V.K. Sibiryakov, R.K. Glushkov, To the diagnosis of toxic metal poisoning $(\mathrm{Pb}, \mathrm{Hg}, \mathrm{Cd})$, Bull. of the Russ. Military Med. Acad., 36(2 S1), 55 (2017)

5. G.I. Pavlenko, V.I. Dorozhkin, E.S. Makarova, D.A. Drozdov, The effect of certain types of fertilizers on the content of nitrates in the soil and their migration in the soil-plant system, Veterin. Med. and Feed., 3, 30-31 (2014)

6. Nitrates, nitrites and N-nitroso compounds, Joint publication of the United Nations Environment Program and the World Health Organization (World Health Organization, Geneva)

7. A.M. Malov, V.K. Sibiryakov, A.A. Ivanenko, The accumulation of cadmium in some organs and tissues of rats, Medline.ru. Russ. Biomed. J. 14(2), 228-240 (2013)

8. L.L. Zakharova, G.A. Zhorov, V.N. Obryvin, An integrated approach to ensuring the safety of livestock products in conditions of technogenic pressure, Russ. J. Probl. of Veterin. Sanit., Hygiene and Ecol., 2(30), 114-120 (2019)

9. V.E. Predtechensky, Clinical Laboratory Research Guide (Moscow, 1960)

10. Handbook of clinical laboratory research methods (Moscow, 1973)

11. S.V. Speransky, On the advantages of using increasing current when studying the ability of white mice to summarize subthreshold impulses, pp. 123124 (Farm. and tox., Moscow, 1965)

12. F.I. Folomeev, Photocolorimetric micromethod for determining $\mathrm{SH}$-groups of a protein and non-protein compounds of blood, Laboratory work, 1, 33-35 (Moscow, 1981)

13. N.G. Stepanova, A modified method for the study of liver function in small laboratory animals, Laboratory work, 5, 49-52 (Moscow, 1962)

14. M.A. Belenky, Quantitative pharmacological effect experiments (Leningrad, 1983)

15. O.I. Tsyganenko, M.V. Naboka, V.S. Lanchenko, Metabolism of nitrates in the human body and animals when they enter drinking water and food, Hygiene and sanitation, 4, 55-59 (1989) 